\title{
Pitavastatin: evidence for its place in treatment of hypercholesterolemia
}

This article was published in the following Dove Press journal:

Core Evidence

21 October 2010

Number of times this article has been viewed

\section{Peter Alagona, Jr}

Penn State Heart and Vascular Institute, Penn State College of Medicine, Hershey, Pennsylvania, USA
Abstract: Statins, inhibitors of 3-hydroxy-3-methylglutaryl-coenzyme A reductase, are the most potent pharmacologic agents for lowering total cholesterol (TC) and lowdensity lipoprotein cholesterol (LDL-C). They have become an accepted standard of care in the treatment of patients with known atherosclerotic cardiovascular disease (secondary prevention) and also those at increased risk of cardiovascular events. There are currently six statin drugs commercially available in the US. Although they are chemically similar and have the same primary mechanisms of action in lowering TC and LDL-C, there are differences in their efficacy or potency, metabolism, drug-drug interactions, and individual tolerability. Considering the numbers of patients who need LDL-C-lowering therapy and questions of individual tolerance and therapeutic response, having a variety of agents to choose from is beneficial for patient care. This paper presents background information on statin treatment and reviews data regarding a new agent, pitavastatin, which has recently been approved for clinical use.

Keywords: HMG CoA reductase inhibitors, statins, pitavastatin, class effect, low-density lipoprotein

Core Evidence outcomes summary for Pitavastatin in Hypercholesterolemia

\begin{tabular}{|c|c|c|}
\hline Outcome measure & Evidence & Implications \\
\hline $\begin{array}{l}\text { Disease-oriented } \\
\text { evidence }\end{array}$ & $\begin{array}{l}\text { Competitive lipid-modifying } \\
\text { efficacy } \\
\text { Documented anti- } \\
\text { atherosclerosis } \\
\text { effects } \\
\text { Beneficial metabolic differences } \\
\text { compared to other available } \\
\text { statins (non-CYP type) and } \\
\text { lack of known drug-drug } \\
\text { interactions to date }\end{array}$ & $\begin{array}{l}\text { Provides another therapeutic choice } \\
\text { for a large patient population. } \\
\text { Considered a surrogate marker for } \\
\text { clinical outcomes and may provide } \\
\text { additional impetus for clinical use. } \\
\text { May provide an important choice in } \\
\text { certain patients or subgroups with statin } \\
\text { contraindications or prior documented } \\
\text { problematic drug-drug interactions. }\end{array}$ \\
\hline $\begin{array}{l}\text { Patient-oriented } \\
\text { evidence }\end{array}$ & $\begin{array}{l}\text { No randomized clinical trial } \\
\text { outcome data }\end{array}$ & $\begin{array}{l}\text { Considering lack of significant outcome } \\
\text { data (even in light of class effect) } \\
\text { compared to other available statins as } \\
\text { well as the massive amount of clinical } \\
\text { experience with other products } \\
\text { pitavastatin uptake and use may be } \\
\text { limited. } \\
\text { (Continued) }\end{array}$ \\
\hline
\end{tabular}

Correspondence: Alagona Penn State Heart and Vascular Institute, Penn State College of Medicine, 500 University Drive, Room C5833, Hershey, PA 17033, USA

Tel + I 7175311790

Fax +I 7175451863

Email palagona@comcast.net 


\begin{tabular}{|c|c|c|}
\hline $\begin{array}{l}\text { (Continued) } \\
\text { Outcome measure }\end{array}$ & Evidence & Implications \\
\hline $\begin{array}{l}\text { Economic } \\
\text { evidence }\end{array}$ & $\begin{array}{l}\text { Statin use in appropriately } \\
\text { defined patient populations } \\
\text { is considered cost-effective } \\
\text { and universally covered } \\
\text { by third party payers }\end{array}$ & $\begin{array}{l}\text { Medical professionals are often wary } \\
\text { of new products and concerned over } \\
\text { potential side-effects and toxicity. } \\
\text { There is always concern over potential } \\
\text { problems not exposed in initial trials and } \\
\text { larger clinical experience (post-marketing } \\
\text { surveillance) is always helpful. This was } \\
\text { clear with the first statin, lovastatin, even } \\
\text { after FDA approval, as well as the last } \\
\text { one, rosuvastatin, especially regarding } \\
\text { potential muscle toxicity. } \\
\text { Although pitavastatin has convincing } \\
\text { efficacy and safety data available, as } \\
\text { much as other commercially available } \\
\text { statins at the time of their FDA } \\
\text { approval, cost considerations have } \\
\text { become a constant in day to day } \\
\text { practice. The presence of multiple } \\
\text { other competitive statins, including } \\
\text { generic "equivalent" products, and } \\
\text { the anticipated higher cost of a new } \\
\text { brand-name drug will present significant } \\
\text { challenges to this pharmaceuticals use. }\end{array}$ \\
\hline
\end{tabular}

\section{Introduction}

Dr Akira Endo at Sankyo Laboratories in Japan is credited with isolating and identifying ML-236B from the fungus Penicillium citrinum more than 30 years ago. ${ }^{1}$ Named mevastatin, this was the first 3-hydroxy-3-methylglutaryl-coenzyme A (HMG-CoA) reductase inhibitor. However, due to questionable toxicity in experimental animals, it was never developed commercially. Merck \& Company later isolated MK803, or mevinolin, from Aspergillus terreus in 1976. This drug was found to lower total cholesterol (TC) and low-density lipoprotein cholesterol (LDL-C) significantly, with an acceptable safety profile, and resulted in the approval and commercial release of lovastatin. Subsequently, a series of HMG-CoA reductase inhibitors were developed and approved for clinical use. These drugs are now known simply as statins.

Dozens of major clinical trials, with hundreds of thousands of subjects enrolled, have consistently revealed not only significant LDL-C-lowering efficacy and outstanding safety, but more importantly, major reductions in almost all clinical manifestations of atherosclerotic disease including coronary events, stroke, and incidence of revascularization. As a result, morbidity and mortality in every patient group studied has been significantly decreased. Statins have revolutionized the prevention and treatment of atherosclerotic cardiovascular disease.

Of the six statins available, three were isolated from fungi (lovastatin, simvastatin, pravastatin) and three synthesized in the laboratory (fluvastatin, atorvastatin, rosuvastatin). All contain a dihydroxy heptanoic acid moiety similar to
HMG-CoA and competes with it for binding with HMG-CoA reductase (Figure 1). There are other chemical groups or moieties which also participate in this competitive binding ${ }^{2}$ and enzyme inhibition.

The synthesis of sterols, including cholesterol, begins with acetyl CoA. However, the rate-limiting enzymatic reaction is two steps further down the chain with the conversion of HMG-CoA to mevalonate by HMG-CoA reductase. Statins inhibit this reaction and the production of mevalonate, thereby reducing cholesterol synthesis (Figure 2). The number and type of chemical bonds a statin can establish with HMG-CoA reductase determines its potency and therefore determines its effects on cholesterol production. ${ }^{2}$ Decreased production of cholesterol decreases the hepatic intracellular pool and subsequently provokes increased transcription of LDL receptors on the surface of hepatocytes. These receptors bind with apoproteins $\mathrm{B}(\mathrm{apoB})$ and $\mathrm{E}(\mathrm{apoE})$ on the surface of very low-density lipoprotein (VLDL) and its remnant particles, including LDL, intermediate density lipoprotein (IDL), and lipoprotein (a) $[\mathrm{Lp}(\mathrm{a})],{ }^{3}$ resulting in increased uptake and decreased plasma levels of these particles. This is the major mechanism leading to significant reduction of not only LDL-C but all apoB particles (Figure 3). Statins also decrease VLDL and apoB production in the liver. ${ }^{4}$ Powerful reduction of plasma $\mathrm{TC}$ and apoB lipoproteins does not appear to lead to any known harmful structural (cellular, tissue) or metabolic perturbations in adults. A variety of nonstatin treatments resulting in TC-lowering, including ileal 
<smiles>C=C(C[C@](C)(O)CC(=O)OC)SC(=O)O</smiles>

HMG-CoA<smiles>COC(=O)C[C@@H](O)CC(O)/C=C/c1c(-c2ccc(F)cc2)c2ccccc2n1C(C)C</smiles>

Fluvastatin<smiles>CCC(C)(C)C(=O)Oc1cc(C)cc2ccc(C)c(C[14c]3cc(O)cc(=O)o3)c12</smiles>

Simvastatin<smiles>CC[C@H](C)C(=O)Oc1cc(C)cc2ccc(C)c(CC=Cc3cc(O)cc(=O)o3)c12</smiles>

Lovastatin

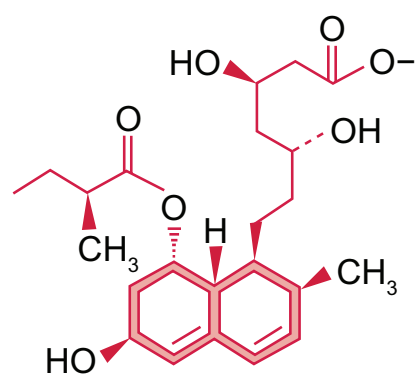

Pravastatin<smiles>COC(=O)C[C@@H](O)CC(O)/C=C/c1c(-c2ccc(F)cc2)c(-c2ccccc2)c(C(=O)Nc2ccccc2)n1C(C)C</smiles>

Atorvastatin<smiles>COC(=O)C[C@@H](O)CC(O)/C=C/c1c(C2=C=C=C(F)C=C2)nc(N(C)S(C)(=O)=O)nc1C(C)C</smiles>

Rosuvastatin

Figure I Statins share a number of chemical similarities. They all contain a dihydroxy heptanoic acid HMG-CoA like moiety, which competes for binding to HMG-CoA reductase. The fungal statins all have a naphthalenyl ester base structure. The synthetic statins share a fluorinated phenyl group with a methylethyl side chain and a base structure with five or six-member ring with one or more carbon atoms replaced by nitrogen. All these structural elements participate in binding to HMG-CoA reductase. Copyright (C) 2009. Adapted with permission from McKenney JM, Ganz P, Wiggins BS, et al. In: Ballantyne CM, editor. Clinical Lipidology A Companion to Braunwald's Heart Disease. Philadelphia, PA: Saunders Elsevier; 2009.

bypass $^{5}$ and use of the bile acid sequestrant, cholestyramine, have also led to decreased cardiovascular events. ${ }^{6}$

Major clinical benefits from statin treatment appear secondary to lowering of LDL-C. ${ }^{7}$ However, numerous experimental and clinical studies have revealed a number of other actions or pleiotropic effects that may also affect atherosclerosis and outcomes including:

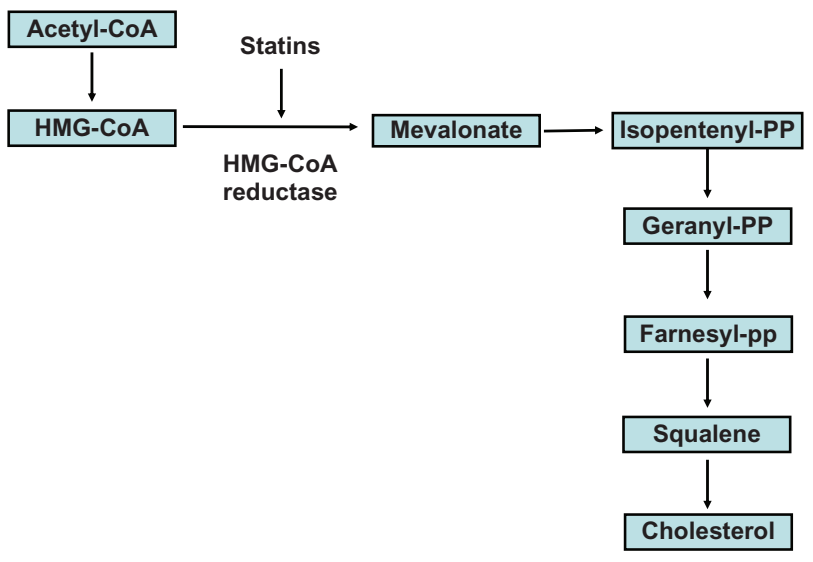

Figure 2 The rate limiting step in the conversion of Acetyl CoA to cholesterol is 3-hydroxy-3-methylglutaryl-CoA to mevalonate. This reaction is mediated by the enzyme HMG-CoA reductase and HMG-CoA reductase inhibitors, or statins, competitively inhibit this activity.
- Reduction of inflammatory markers, including high-sensitivity C-reactive protein (hsCRP) and evidence of vascular inflammation ${ }^{8-11}$

- Rapid improvement in endothelial function ${ }^{12-15}$

- Plaque stabilization and atherosclerosis regression. ${ }^{8,15}$

\section{Statin pharmacokinetics}

The term "class effect" is now used to describe groups of drugs which have the same basic mechanism of action. Statins are all HMG CoA reductase inhibitors, however, as with all drugs in any class, each is unique and can exhibit significant differences in chemical structure, bioavailability, enzyme-binding characteristics, tissue penetration and retention, half-life, metabolism and elimination, potency, dosage and efficacy, drug-drug interactions, and safety.

Drugs in a class are not identical, and it should not be assumed that they will behave identically in different individuals. Some drugs in a class have a wealth of data including outcomes supporting their use and others little. Class effect is a simplistic term and its use, unfortunately at times, may inappropriately affect therapeutic choices. 


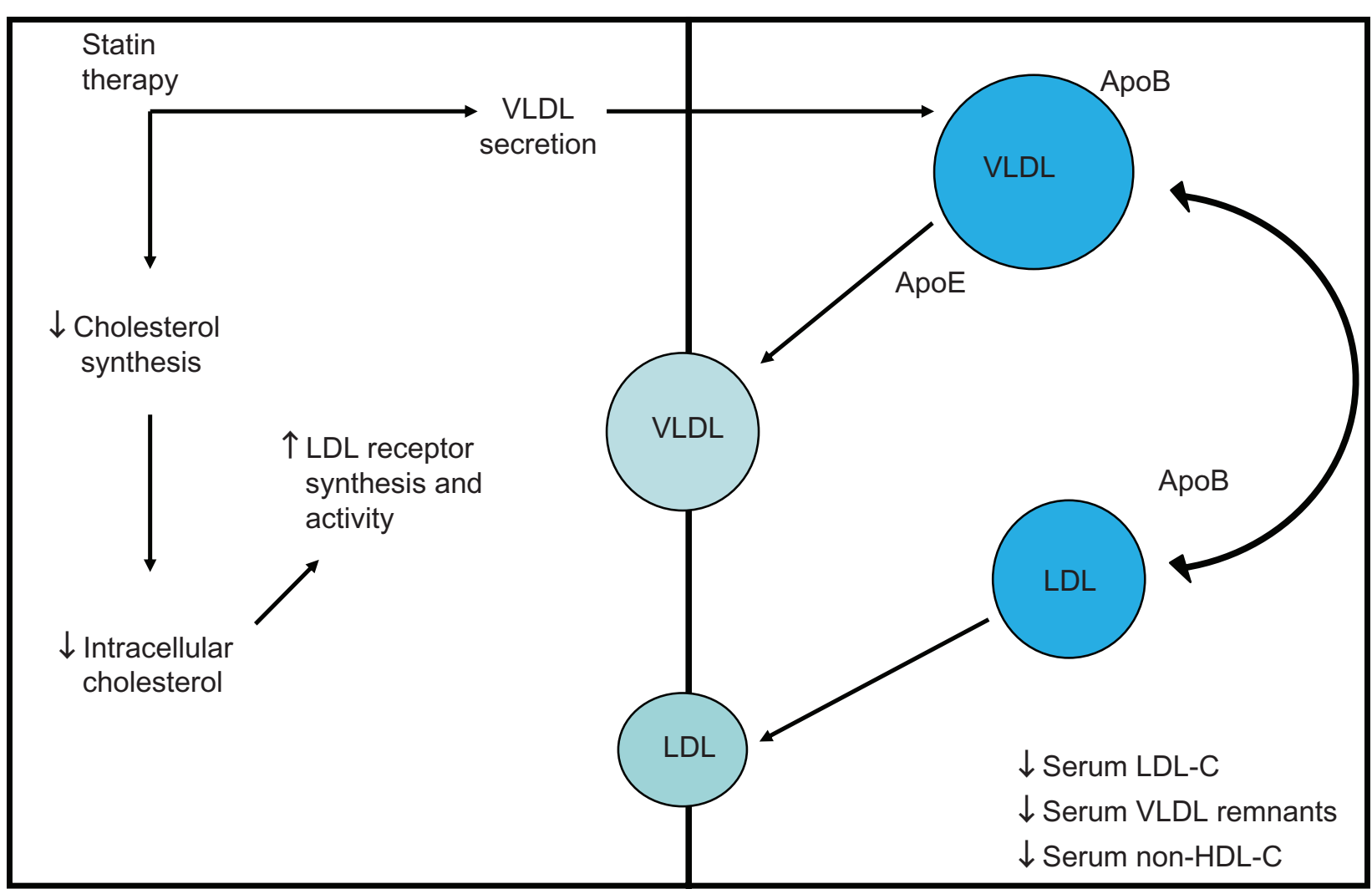

Hepatocyte

Systemic circulation

Figure 3 HMG-CoA reductase inhibitors (statins) reduce TC and LDL-C via a number of mechanisms: Decreased hepatic synthesis of cholesterol, decreased hepatic intracellular cholesterol pool stimulating upregulation of LDL receptor activity, reduced VLDL secretion from hepatocytes leading to decreased remnant lipoproteins and increased tissue uptake of apoB particles from the circulation.

Table 1 summarizes a number of pharmacokinetic features of all currently available statins including pitavastatin.

Lovastatin and simvastatin are prodrugs which require metabolic modification in the gut and liver with hydrolysis of a lactone group to produce the active acid form. Statins vary in their tissue solubility, some being predominantly lipophilic or fat soluble, and others being more hydrophilic or water soluble. Although the lipophilic agents penetrate cell membranes more readily, there is no evidence that this affects lipid-modifying efficacy, outcomes, or toxicity.

These drugs exhibit limited bioavailability, with $<25 \%$ of an orally administered dose reaching the circulation. Because muscle toxicity is directly related to serum statin levels, this limited bioavailability may actually simplify clinical use by creating a large therapeutic:toxicity ratio at all commercially available doses. Greater than $80 \%$ of their dose is excreted via the liver and gut with only a minimal amount by the kidneys. Half-lives vary, being 1-3 hours for lovastatin, simvastatin, pravastatin, and fluvastatin, and 14-19 hours for atorvastatin and rosuvastatin.
Simvastatin and lovastatin are metabolized by cytochrome (CYP) 3A4 enzymes, part of the CYP450 system in the liver, and also undergo glucuronidation followed by lactonization in the liver. They are then converted to an open-acid form and excreted in bile and urine. Atorvastatin metabolism is less dependent on this system. Fluvastatin and rosuvastatin are eliminated mainly as the parent compound without major modification, via bile and urine. Pravastatin is not metabolized by the P450 system.

Because serum lipoproteins have half-lives of 203 days, even short-acting statins can be administered on a daily basis. Because cholesterol synthesis peaks at night, statins are usually dosed in the evening, although this may be less important for those agents with longer half-lives. However, no significant differences in efficacy have been documented when they are administered at different times of day.

Table 2 provides a list of drugs that may affect statin metabolism. The most concerning interaction involves drugs that compete for CYP3A4 enzyme metabolism in the liver. Elimination of atorvastatin, simvastatin, and lovastatin may be affected when administered with other drugs that 
compete for CYP3A4 metabolism. The result is increased area-under-the-curve (AUC) and peak concentration for these statins, potentially increasing the risk of muscle toxicity. The most important drug groups are the azole antifungals (except for fluconazole), macrolide antibiotics (except azithromycin), protease inhibitors, some antidepressants, and grapefruit juice. ${ }^{16-18}$ The nondihydropyridine calcium channel blockers (diltiazem, verapamil) are also metabolized by this same system, and may increase serum lovastatin and simvastatin levels. There is considerable concern with regard to statinfibrate combinations, but data reveal that the risk is basically limited to statin-gemfibrozil combinations and is not due to CYP interactions but to competition for glucuronidation with certain statins. To date, there are no cogent data indicating a significantly increased risk of muscle or liver toxicity with fenofibrate, and a newer fenofibric acid product has Food and Drug Administration (FDA) approval for use with low- and moderate-dose statin therapy. ${ }^{19}$ Atorvastatin is less dependent on CYP3A4 metabolism and there is less risk of significantly increased plasma levels. Because pravastatin, fluvastatin, and rosuvastatin are not metabolized using this pathway, there is less concern when combining these agents with other selective CYP3A4 inhibitors. Although the statins are all in the same class, they have significant differences in their metabolism and elimination, as well as drug-drug interactions.

\section{Clinical efficacy and outcomes}

Statins exhibit different lipid/lipoprotein-modifying effects, and the most significant clinically is LDL-C-lowering potency. There are substantial trial data indicating fairly predictable lipid-modifying efficacy for each statin. Response and efficacy may be affected by patient nonadherence, genetic mutations affecting LDL structure (apoB) and receptor activity, as well as initial lipid values prior to treatment. The STELLAR (Statin Therapies for Elevated Lipid Levels Compared Across Doses to Rosuvastatin) trial was a six-week, randomized, parallelgroup, open-label, comparator-controlled trial in 2431 adults with hypercholesterolemia. STELLAR was adequately powered to compare lipid and lipoprotein responses for all statins tested. ${ }^{20}$ The results revealed that, on a milligram per milligram basis, rosuvastatin was the most potent at LDL-C-lowering followed by atorvastatin, simvastatin, and pravastatin. STELLAR also showed greater attainment of the National Cholesterol Education Program Adult Treatment Panel III (NCEP ATP III) ${ }^{21}$ goals using rosuvastatin in patients with known coronary heart disease (CHD) and risk equivalents. This included goals for LDL-C, triglycerides (TG), and non-high-density cholesterol (non-HDL-C).
Patients with atherosclerotic cardiovascular disease and even mildly elevated TG $>200 \mathrm{mg} / \mathrm{dL}$ can have the atherogenic dyslipidemia ${ }^{22}$ characterized by decreased HDL-C and increased TG. The presence of elevated TG may lead to increased levels of atherogenic apoB lipoproteins, including VLDL and remnant particles IDL, Lp(a), and small dense (Pattern B) LDL. Although LDL-C, as defined by NCEP ATP III, is the primary target of therapy in these patients, calculated LDL-C levels may not accurately reflect the number and atherogenic potential of all apoB particles. Increased LDL particle number can occur even with relatively unremarkable calculated LDL-C levels. In this population, LDL particle number may be a better predictor of cardiovascular risk than calculated LDL-C, and treatment might also be directed at lowering the number of apoB particles. Statins lead to removal of VLDL and LDL from plasma, leading to reduction in particle number. Smaller denser particles appear to be preferentially removed. ${ }^{23-25}$ The STELLAR trial also revealed that statins are effective at lowering non-HDL- $\mathrm{C}^{20}$ by all the mechanisms noted. Non-HDL-C, a simple calculation (TC-HDL-C), may be a more accurate way of estimating apoB and atherogenic potential. NCEP ATP III indicates non-HDL-C as a secondary target of therapy and recommends a goal of $30 \mathrm{mg} / \mathrm{dL}$ above the chosen LDL-C goal.

Statins usually lead to minimal or modest increases in HDL-C which are not as predictable as their LDL-C-lowering effects. However, even modest increases in HDL-C may be important. In the Scandinavian Simvastatin Survival Study (4S) a mean dose of $27 \mathrm{mg}$ of simvastatin led to a mean increase in HDL-C of $6 \%$, which was enough to contribute to improved outcomes. ${ }^{26}$ Currently, rosuvastatin provides the greatest increase in HDL-C levels, frequently $>10 \%$ at higher doses. When HDL-C levels are decreased, it might be beneficial to consider using statins that increase HDL-C in a more predictable fashion.

There are a massive amount of clinical trial data regarding the benefits of statin treatment across a spectrum of cardiovascular disease and risk reduction, including CHD, death, nonfatal myocardial infarction (MI), acute coronary syndrome (ACS), and stroke. There are significant reductions in morbidity and mortality with relative risk reduction of approximately $30 \%$ in the secondary population. ${ }^{26-28} \mathrm{An}$ analysis of 14 trials with 90,056 subjects enrolled determined that, for every $1 \%$ LDL-C-lowering with statins, there is a $0.88 \%$ reduction in first CHD events. This relationship begins when LDL-C reduction is $>20 \%$ over the baseline because all the statin trials evaluated achieved this level of reduction. The elderly obtain similar benefit from LDL-C-lowering 
with statins, as noted in the PROSPER (PROspective Study of Pravastatin in the Elderly at Risk) ${ }^{29}$ and Cholesterol Treatment Trialists Collaborators studies. ${ }^{7}$ Diabetic patients treated with statins achieve great benefit with significant reductions in events. ${ }^{28,30,31}$ It should be noted that even with the most aggressive, higher-dose statin studies, there is significant residual risk of cardiovascular events. ${ }^{15,32}$ These are the events that continue to take place in treated patients, even when LDL-C goals are achieved. However, ATP III LDL-C goal attainment remains unsatisfactory at $<40 \%$ in diabetic patients and $<60 \%$ for those with known CHD. ${ }^{33}$ The availability of more potent statins improves goal attainment. Statins appear safe in the pediatric ( $>$ two years of age) and adolescent population. ${ }^{34}$ However, there are no published outcome studies in this population.

\section{Pitavastatin}

\section{Pharmacokinetics}

Pitavastatin is a potent HMG-CoA reductase inhibitor which induces a substantial increase in LDL receptor activity and lowers LDL-C. It has a characteristic structure (Figure 4) with a quinoline ring at the core, a cyclopropyl moiety, and a flourophenyl group, similar to other statins, especially fluvastatin and rosuvastatin. ${ }^{35}$ This structure improves pharmacokinetics, with better absorption and activity (Table 1$).{ }^{36}$ After oral administration of C-14-labeled pitavastatin, the concentration is 54 times greater in the liver than in serum. Pitavastatin is more potent at inhibiting cholesterol synthesis in vitro and is more effective at induction of LDL receptor expression and activity than any other statin. ${ }^{37} \mathrm{In}$ isolated rat liver microsomes, pitavastatin inhibited HMG-CoA reductase activity in a concentrationdependent manner, with an $\mathrm{IC}_{50}$ of $6.8 \mathrm{nmol} / \mathrm{L}, 2.4$-fold higher

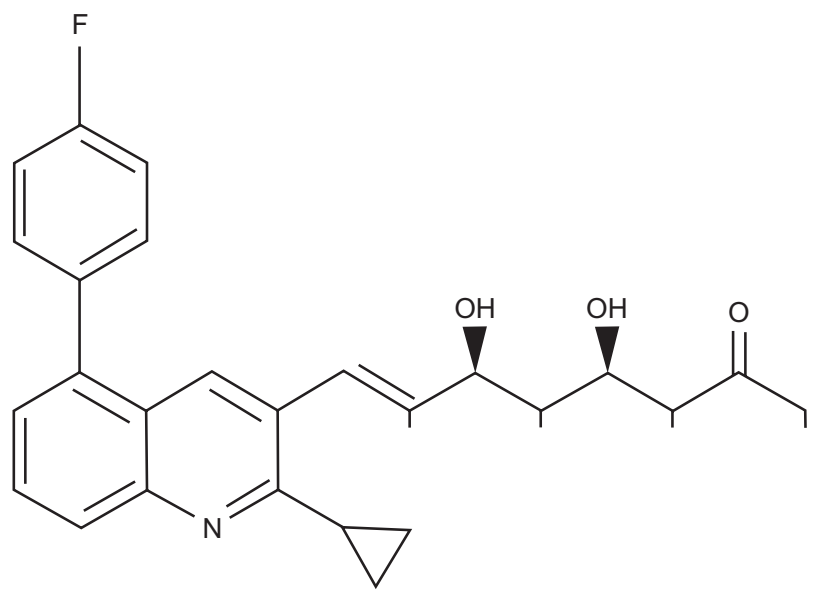

Figure 4 Chemical structure of pitavastatin. Note commonality to other statins in Figure I. than simvastatin and 6.8-fold higher than pravastatin. Similar results were obtained in a cultured human hepatoma cell line, with pitavastatin having a two-fold higher affinity for HMGCoA reductase inhibition than simvastatin and a 5.7-fold higher affinity than atorvastatin. These data imply that pitavastatin is a stronger inhibitor of HMG-CoA reductase activity than any other statin, including rosuvastatin. ${ }^{38}$ Using the same cultured human hepatoma cell model, pitavastatin was found to have a superior ApoA-1 secretion-promoting effect compared with simvastatin and atorvastatin. ${ }^{39}$

Pitavastatin has $>80 \%$ bioavailability in rats and dogs, and is selectively taken up by the liver. ${ }^{36}$ Figure 5 illustrates the metabolic pathway for pitavastatin. Numerous lipophilic drugs are metabolized in the liver by the CYP450 system. Statins also utilize this pathway, simvastatin and atorvastatin via CYP3A4 and fluvastatin by CYP2C9. Pitavastatin is lipophilic, but only minimally metabolized by CYPs. It undergoes rapid glucuronidation by a series of enzymes and is then converted to its inactive lactone form by elimination of glucuronic acid. ${ }^{40-42}$ There is minimal metabolism by CYP2C9 which does not appear significant. ${ }^{42}$ Metabolic properties of pitavastatin are similar to the hydrophilic statins, pravastatin and rosuvastatin, and it is classified as a non-CYP type. Administering pitavastatin $4 \mathrm{mg}$ and atorvastatin $20 \mathrm{mg}$ with grapefruit juice (a CYP3A4 inhibitor) revealed an $83 \%$ increase in the AUC for atorvastatin and only $13 \%$ for pitavastatin, ${ }^{43}$ consistent with insignificant CYP interaction. Another study concluded that pitavastatin compared with other statins did not significantly inhibit CYP metabolism of a number of other substrates. ${ }^{44}$ These data indicate that pitavastatin has little drug-drug interaction via CYP competition, especially CYP3A4, and therefore may be safer to use than other statins in combination with a variety of CYP-metabolized drugs. The renal excretion rate amounts to $2 \%$, with a terminal half-life of 11 hours, suggesting pitavastatin is a long-acting HMG-CoA reductase inhibitor. ${ }^{45}$

In a small study of six elderly aged $>65$ years versus five nonelderly aged $22-24$ years, subjects received repeated oral administration of pitavastatin $2 \mathrm{mg}$ daily for five days. The elderly subjects did not exhibit different pharmacokinetic properties. ${ }^{42}$ It does not appear from preliminary studies that there is a difference in potential toxicity in the elderly or that dose adjustment is necessary.

\section{Ability to lower LDL-C}

As with all statins, lowering of LDL-C, as well as safety risk, increases in a dose-dependent fashion. ${ }^{46}$ The greatest 
Table I Pharmaticokinetic variables of marketed statins

\begin{tabular}{|c|c|c|c|c|c|c|c|}
\hline Variable & Pitavastatin & Atorvastatin & Fluvastatin & Lovastatin & Pravastatin & Rosuvastatin & Simvastatin \\
\hline Prodrug & No & No & No & Yes & No & No & Yes \\
\hline Lipophilcity (log P) & 1.49 & 4.06 & 3.24 & 4.30 & -0.23 & 0.13 & 4.68 \\
\hline $\mathrm{T}_{\max }$ & $0.5-0.8$ & I.0-2.0 & $<1.0$ & $2.0-4.0$ & $1.0-1.5$ & $3.0-5.0$ & 4.0 \\
\hline T I/2 (h) & 11 & 14 & $<3$ & 2 & 2 & 19 & $1.4-3.0$ \\
\hline Absorption (\%) & 80 & 30 & 98 & 30 & 3.4 & $40-60$ & $60-80$ \\
\hline Bioavailability (\%) & 60 & 14 & 24 & $<5$ & 17 & 20 & $<5$ \\
\hline Protein binding (\%) & 96 & $>98$ & 98 & $>95$ & 50 & 88 & 95 \\
\hline $\begin{array}{l}\text { Major P450 metabolic } \\
\text { enzyme }\end{array}$ & CYP2C9 & CYP3A4 & $\begin{array}{l}\text { CYP2C9 } \\
\text { (minor) }\end{array}$ & CYP3A4 & None & $\begin{array}{l}\text { CPY2C } \\
\text { (minor) }\end{array}$ & CPY3A4 \\
\hline $\begin{array}{l}\text { Systemic active } \\
\text { metabolites ( } n \text { ) }\end{array}$ & No & Yes (2) & No & Yes (4) & No & Minimal & Yes (3) \\
\hline Renal excretion (\%) & 2 & $<2$ & $<6$ & 10 & 20 & 10 & 13 \\
\hline
\end{tabular}

Note: This table lists the most important pharmacokinetic variables for all available statins including pitavastatin. The noteworthy difference which often effects drug selection is the metabolic pathway, especially utilizing the CYP system, leading to drug-drug competition for metabolism and subsequent interactions. Log P or the logarithm of partial coefficient of statins relates to lipophilicity (the higher the $\log P$ the more lipid soluble).

percent LDL-C-lowering occurs at the starting dose for all these drugs. Initial LDL-C-lowering effects vary depending on statin potency, and can be anywhere from $>20 \%$ with the weaker drugs and $>40 \%$ with more powerful agents. Each incremental dose commonly reduces LDL-C by another $6 \%-7 \%$. Pitavastatin belongs in the category of potent statins, with atorvastatin and rosuvastatin causing similar lowering of LDL at comparable doses (Table 3). In one of the first dose-finding studies done in Japanese patients with elevated cholesterol, pitavastatin lowered LDL-C after 12 weeks by $34 \%$ at $1 \mathrm{mg}, 42 \%$ at $2 \mathrm{mg}$, and $47 \%$ at $4 \mathrm{mg}$ (Figure 6 ). ${ }^{47}$ A Phase III study in Europe revealed mean percent reduction in LDL-C following 12-week administration of pitavastatin $2 \mathrm{mg}(\mathrm{n}=315)$ and $4 \mathrm{mg}(\mathrm{n}=298)$ to be $38 \%$ and $45 \%$, respectively, which was comparable with that in the control group taking atorvastatin $10 \mathrm{mg}$ and $20 \mathrm{mg} .{ }^{48} \mathrm{~A}$ number of other studies with pitavastatin alone or compared with other statins, including pravastatin, simvastatin, and atorvastatin, consistently reveal potent lowering of LDL-C. ${ }^{49-51}$ Efficacy was also evaluated in 30 heterozygous familial hypercholesterolemia patients. LDL-C decreased by $40 \%$ after eight weeks using pitavastatin $2 \mathrm{mg}$ and by $48 \%$ using $4 \mathrm{mg} .{ }^{52}$

\section{Non-LDL-C factors}

Substantial epidemiologic, experimental, and clinical evidence supports the important protective role of HDL in the prevention of atherosclerosis and cardiovascular events. Although data regarding reduction of events with

Table 2 Drug interactions with statins

\begin{tabular}{|c|c|c|c|c|c|c|}
\hline Variable & Atorvastatin & Fluvastatin & Lovastatin & Pravastatin & Rosuvastatin & Simvastatin \\
\hline Major P450 & CYP3A4 & CYP2C9 & CYP3A4 & None & CYP2C9 & CYP3A4 \\
\hline metabolic enzyme & & CYP2C8 & & & (minor) & \\
\hline Azole antifungals & Yes & No & Yes & No & No & Yes \\
\hline $\begin{array}{l}\text { Nondihydropyridine } \\
\text { calcium-channel } \\
\text { blockers }\end{array}$ & Rare cases & No & $\begin{array}{l}\text { Yes (up to a fourfold } \\
\text { increase in statin } \\
\text { blood level) }\end{array}$ & No & No & $\begin{array}{l}\text { Yes (up to a fourfold } \\
\text { increase in statin } \\
\text { blood level) }\end{array}$ \\
\hline Amiodarone & NR & No & Yes & No & No & Yes \\
\hline Cyclosporine & Yea & NR & Yes & Yes & Yes & Yes \\
\hline $\begin{array}{l}\text { Macrolide } \\
\text { antibiotics }\end{array}$ & No & No & Yes & No & No & Yes \\
\hline Gemfibrozil & NR & No & Yes & Yes & Yes & Yes \\
\hline Fenofibrate & NR & NR & NR & No & No & No \\
\hline $\begin{array}{l}\mathrm{HVI} \text { protease } \\
\text { inhibitors }\end{array}$ & Yes & No & Yes & No & No & No \\
\hline Warfarin & No & No & Yes & No & Yes & No \\
\hline Antidepressants & Yes & No & Yes & No & No & Yes \\
\hline
\end{tabular}

Note: Statins have numerous drug-drug interactions with multiple other groups/classes which often affect treatment decisions. However even within the statin class there are differences among products. Pitavastatin has limited published data currently available however in clinical trials and a reported large post-marketing surveillance study no specific drug-drug interactions of significance have been noted (NR not reported). ${ }^{16,18}$ 
Pitavastatin metabolite M-13

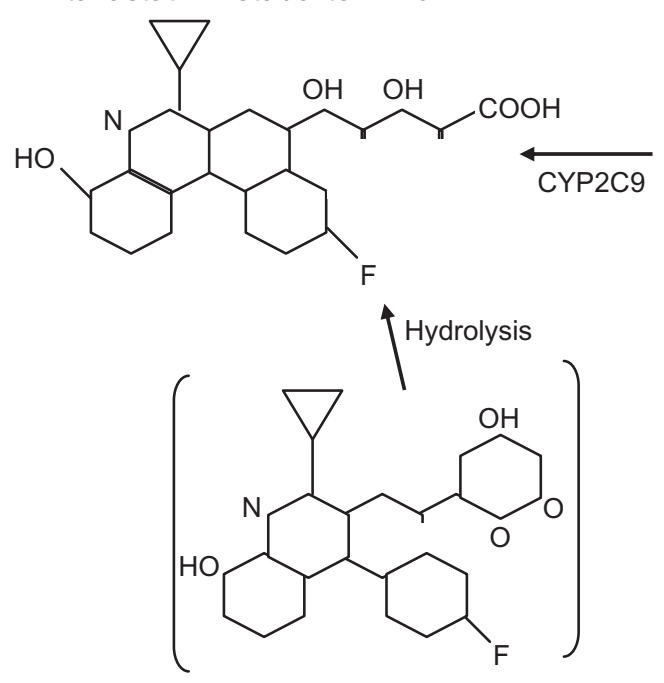

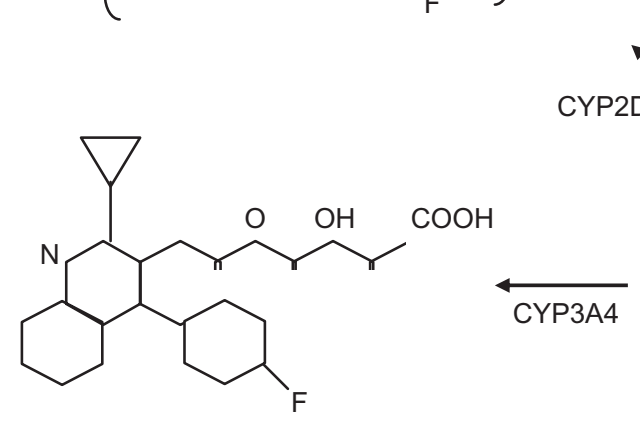

Pitavastatin metabolite M-3
Pitavastatin

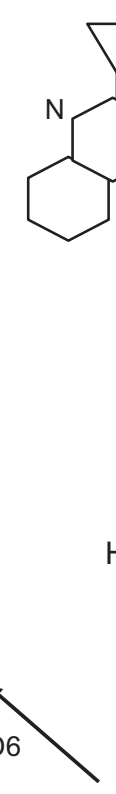

Figure 5 Metabolic pathway for pitavastatin. Involvement of CYP2C9 is minimal. It is rapidly glucuronized by uridine diphosphate-glucuronyl transferase (UGT) and then converted to a lactone form which is inactive.

pharmacologic interventions to increase HDL-C are less robust than that for LDL-C- lowering, it may play an important role in future preventive efforts. In addition to potent LDL-C lowering pitavastatin has substantial efficacy data for increasing HDL-C.

In a Phase III study completed in Japan, pitavastatin $2 \mathrm{mg}$ /day significantly increased HDL by $8.9 \%$. In total, 227 patients with elevated LDL-C (>140 mg/dL) were enrolled (173 treated) in a 52-week, randomized, open-label, parallel-group comparison of the effects of pitavastatin $2 \mathrm{mg}$ and atorvastatin $10 \mathrm{mg}$ on HDL-C. ${ }^{53}$ Pitavastatin increased HDL-C by $8.2 \%$ versus $2.9 \%$ for atorvastatin $(P=0.031)$ and apoA-I by $5.1 \%$ and $0.6 \%$, respectively $(P=0.019)$ with percentage change in LDL-C ( -40.1 versus -33.0$)$. LIVES (Treatment Outcome Study of the LIVALO Effectiveness and Safety $)^{54}$ enrolled 20,279 patients in a long-term (104week), prospective postmarketing surveillance study to evaluate plasma lipids in those receiving pitavastatin. TC was reduced by $21 \%$ and LDL-C by $31.3 \%$. Mean TG were reduced significantly when they were elevated $(>250 \mathrm{mg} /$ dL) prior to treatment. HDL-C increased by 5.9\%; however, in $24.6 \%$ of those who started with HDL-C $<40 \mathrm{mg} / \mathrm{dL}$, it continued to increase between 12 and 104 weeks. HDL-C also increased when patients were switched from other statins (Figure 7).

Pitavastatin's effects on HDL metabolism were evaluated in 29 patients with hypercholesterolemia on $2 \mathrm{mg}$ for four weeks. TC was decreased by $26.9 \%$, LDL by $39.8 \%$, while serum HDL2 and HDL 3 increased by 6.0 and $9.0 \%$, respectively. ${ }^{56} \mathrm{~A}$ Japanese comparative study of pitavastatin and atorvastatin in hypercholesterolemic patients revealed similar effects on non-HDL-C after 12 weeks of treatment with pitavastatin $2 \mathrm{mg}$ or atorvastatin $10 \mathrm{mg}$ (decreased by $39 \%$ versus $40.3 \%$, respectively). However, only pitavastatin significantly increased HDL-C and decreased TG levels. ${ }^{57}$ In patients with pretreatment TG $>150 \mathrm{mg} / \mathrm{dL}$, a Phase III study documented TG reductions of $23 \%$ and $42 \%$ with pitavastatin $2 \mathrm{mg}$ and $4 \mathrm{mg}$, respectively. ${ }^{48,53}$ Although there is no relevant head-to-head or crossover study data, this level of TG-lowering may be comparable with that of most fibrates, as well as high-dose omega-3-acid ethyl esters (omega-3 fish oils or polyunsaturated fatty acids). 
Table 3 LDL lowering efficacy of statins

\begin{tabular}{lll}
\hline Statin & Dose & Average LDL reduction \\
\hline Fluvastatin & $40 \mathrm{mg}$ & $-25 \%$ \\
Lovastatin & $80 \mathrm{mg}$ & $-35 \%$ \\
Simvastatin & $20 \mathrm{mg}$ & $-27 \%$ \\
& $40 \mathrm{mg}$ & $-38 \%$ \\
& $20 \mathrm{mg}$ & $-38 \%$ \\
Pravastatin & $40 \mathrm{mg}$ & $-41 \%$ \\
& $80 \mathrm{mg}$ & $-47 \%$ \\
Atorvastatin & $40 \mathrm{mg}$ & $-34 \%$ \\
& $80 \mathrm{mg}$ & $-37 \%$ \\
& $10 \mathrm{mg}$ & $-39 \%$ \\
& $20 \mathrm{mg}$ & $-43 \%$ \\
Rosuvastatin & $40 \mathrm{mg}$ & $-50 \%$ \\
& $80 \mathrm{mg}$ & $-60 \%$ \\
& $5 \mathrm{mg}$ & $-45 \%$ \\
& $10 \mathrm{mg}$ & $-52 \%$ \\
Pitavastatin & $20 \mathrm{mg}$ & $-56 \%$ \\
& $40 \mathrm{mg}$ & $-63 \%$ \\
& $1 \mathrm{mg}$ & $-34 \%$ \\
& $2 \mathrm{mg}$ & $-42 \%$ \\
& $4 \mathrm{mg}$ & $-47 \%$ \\
\hline Ng & $8 \mathrm{mg}$ & $-55 \%$ \\
\hline
\end{tabular}

Note: Comparative LDL-C lowering efficacy of statins obtained from multiple trials. $^{18,21,48,49,51,66}$

The effect of pitavastatin on small dense LDL as well as other remnant particle cholesterol was evaluated by Nozue et al..$^{58}$ Seventeen patients with heterozygous familial hypercholesterolemia were randomly assigned to either pitavastatin $2 \mathrm{mg}$ or atorvastatin $10 \mathrm{mg}$. LDL-C, small dense LDL, and remnant lipoprotein cholesterol were measured prior to and after 12 weeks of treatment. Pitavastatin decreased small dense LDL by $63 \%$ from baseline and atorvastatin by $55 \%$ (both $P<0.001$ ). Remnant lipoprotein cholesterol was reduced by $16 \%$ with pitavastatin and by $45 \%$ in the atorvastatin group. There were no significant differences in results between the two treatments. Similar studies ${ }^{59,60}$ are consistent with regard to pitavastatin's effects on LDL-C and remnant lipoproteins.

Pitavastatin has potent efficacy in lowering LDL-C and non-HDL-C, in addition to significantly increasing HDL-C and lowering TG. It improves other atherogenic lipid parameters, including decreasing small dense LDL, particle number, and remnant lipoprotein cholesterol. This therapeutic profile may be especially beneficial in those with metabolic syndrome, diabetes mellitus, and atherogenic dyslipidemia.

\section{Pleiotropic effects}

Nonlipid risk factors for atherosclerosis and cardiovascular risk, as mentioned above, may include vascular inflammation ${ }^{61}$ with a variety of markers, including hsCRP. Numerous studies and publications consistently reveal hsCRP to be at least a marker of increased risk, if not an active participant in the process. ${ }^{62}$ Although numerous lipid-modifying drugs lower hsCRP, the statins have the most predictable and potent efficacy when used as monotherapy. ${ }^{9,10}$ Pitavastatin significantly reduced hsCRP in an adult diabetic Japanese population with hypercholesterolemia, even when hsCRP was only mildly elevated. ${ }^{63}$ Like other statins, pitavastatin appears to be a modulator of a variety of vascular and inflammatory markers via inhibition of mRNA expression of interleukin-8, endothelin-1, and plasminogen activator inhibitor-1, along with increased expression of endothelial nitric oxide synthase and thrombomodulin in human umbilical vein endothelial cells. ${ }^{65,66}$ In rats, pitavastatin at therapeutic doses inhibited proliferation and migration of vascular smooth muscle cells via suppression of angiotensin II and platelet-derived growth factor. ${ }^{64,67}$ Statins improve endothelial function rapidly and increase nitric oxide production.

Although plaque stabilization and atherosclerosis regression are often considered to be a surrogate marker for decreased clinical events and result from modification of lipid/metabolic risk, other factors may be involved. Numerous animal and human studies using histologic and various imaging techniques have consistently revealed the beneficial effect of statins. ${ }^{15}$ Using Watanabe heritable hyperlipidemic rabbits, $0.5 \mathrm{mg} / \mathrm{kg}$ of pitavastatin significantly reduced VLDL, IDL, and LDL, and prevented progression of atherosclerosis. ${ }^{68}$ Pitavastatin at $1 \mathrm{mg} / \mathrm{kg}$ in balloon-injured rabbit carotid arteries reduced the risk of restenosis by decreasing neointimal thickening by up to $70 \% .{ }^{69}$ Concomitant reductions in fibronectin and collagen-rich areas by $39 \%$ and $33 \%$, respectively, were noted. Pitavastatin may prevent vascular restenosis by inhibiting smooth muscle cell proliferation and extracellular matrix deposition. Hiro et $\mathrm{a}^{70}$ in a multicenter, prospective, randomized, open-label, parallel-group study utilized intravascular ultrasound in $>300$ patients with ACS. Of these patients, 252 had initial and 8-12 month intravascular ultrasound evaluations to assess percent change in nonculprit plaque volume when comparing atorvastatin $20 \mathrm{mg}$ /day versus pitavastatin $4 \mathrm{mg} /$ day. Results revealed a significant decrease in plaque volume or atheroma burden for both drugs, with no statistical differences between the two. Negative vessel remodeling was also documented. This is consistent with another intravascular ultrasound study in 82 patients undergoing percutaneous coronary intervention. ${ }^{71}$ Forty-one patients were treated with pitavastatin $2 \mathrm{mg} /$ day versus placebo. Significant reduction in plaque volume index occurred with active drug versus placebo $(-10.6 \%$ versus $+8.1 \%)$. There was 


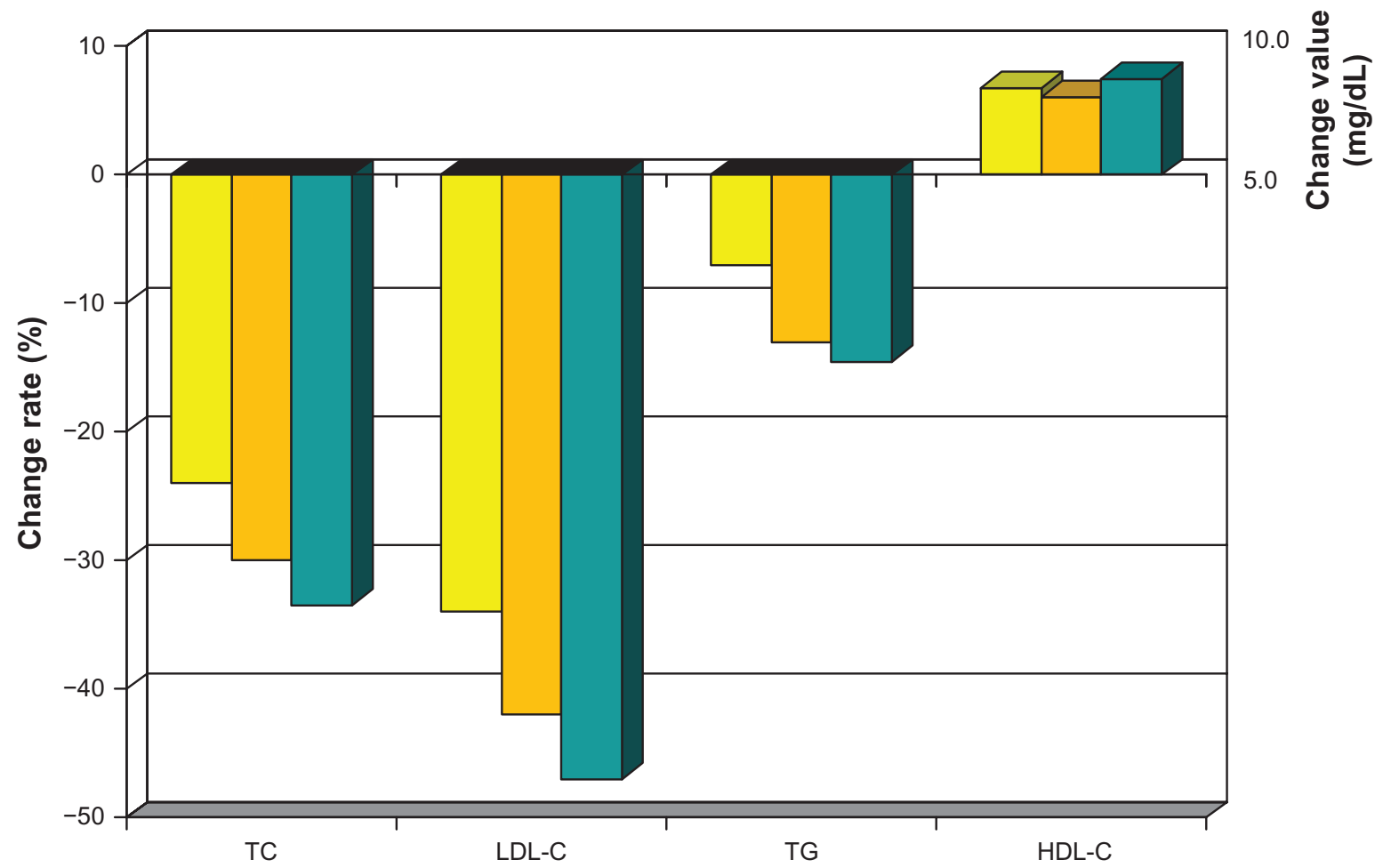

Figure 6 Mean percent change in TC, LDL-C, HDL-C and TG from baseline values with daily dose pitavastatin for 12 weeks: Yellow Bar I mg, Orange Bar 2 mg, Gray Bar 4 mg.

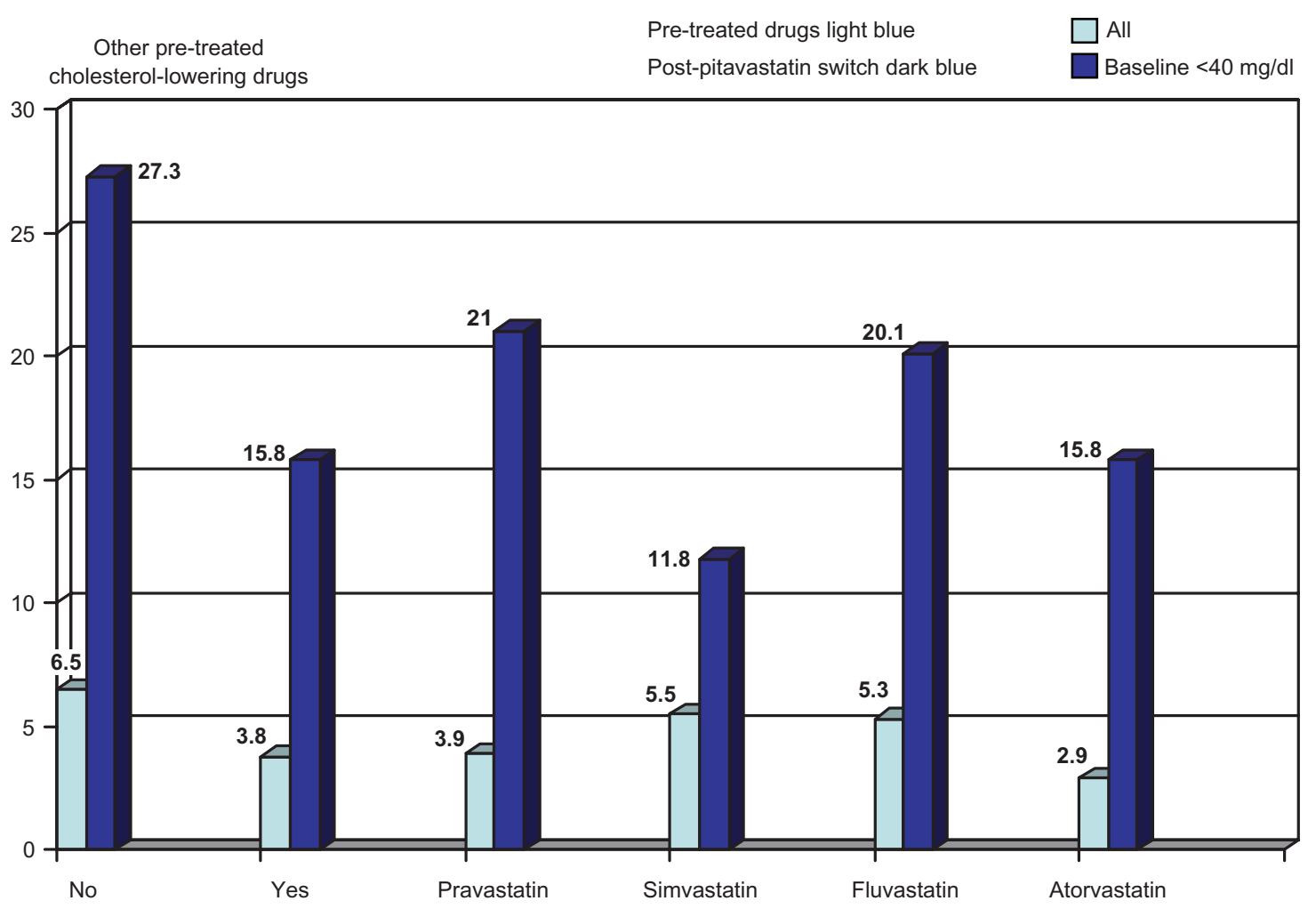

Figure 7 Data obtained from the post-marketing "LIVES Study" assessed standard lipid parameters in large numbers of patients along with a more in-depth analysis of pitavastatin's effect on HDL-C over 104 weeks as well as after switching from other statins. In the low-HDL-C group HDL-C increased $14 \%$ at 12 weeks and $24.6 \%$ at 104 weeks. Significant increases in HDL-C by pitavastatin also occurred after switching from other statins.

Note: \% change in HDL from no initial pharmacologic treatment (light blue bar) versus any lipid therapy (dark blue bar) and the indicated statins after switching to pitavastatin mean dose $<2 \mathrm{mg} /$ day. ${ }^{55}$ 
a close correlation between plaque volume index and LDL-C levels. Nakamura et $\mathrm{al}^{72}$ evaluated the time course of stabilization of echolucent carotid plaques with statin treatment in patients with ACS. Sixty-five patients were identified using carotid ultrasound; 33 received $4 \mathrm{mg}$ pitavastatin and 32 received placebo. The treated group had a significant decrease in echolucent plaque versus placebo. Pitavastatin appears to improve plaque stabilization and increase atherosclerosis regression rapidly and significantly.

\section{Safety and tolerability}

An early Phase II dosing study in the US tested pitavastatin at higher doses of $8,16,32$, and $64 \mathrm{mg}$. There was no dose titration. Within 2-4 weeks, an unacceptable incidence of myotoxicity, defined as myalgia, creatine kinase (CK) levels $>10$ times the upper limit of normal, and myoglobinuria, occurred with doses in excess of $16 \mathrm{mg} .{ }^{73}$ Within two weeks, symptoms resolved and all CK levels returned to normal. Another dose-ranging study utilizing $1-8 \mathrm{mg}$ /day in hyperlipidemic patients for six weeks did not report significantly increased adverse drug reactions (ADR), and at the $8 \mathrm{mg}$ dose LDL-C was lowered by $65 \% .{ }^{74}$ Early clinical trials in Japan revealed ADR defined by signs or symptoms in 50 (5.6\%) of 886 patients, and minor liver enzyme elevations in 167 (18.8\%), similar to the incidence with other statins. ${ }^{75}$ The incidence of ADR was not dose-dependent from 1-4 mg/day. There was no increase in the incidence, severity, or appearance of new ADRs with long-term administration. Double-blind Phase III studies comparing starting doses of pitavastatin $2 \mathrm{mg}$, pravastatin $10 \mathrm{mg}$, simvastatin $20 \mathrm{mg}$, and atorvastatin $10 \mathrm{mg}$, revealed similar safety profiles. ${ }^{4-50}$ The LIVES study,${ }^{54}$ which enrolled over 20,000 patients with hypercholesterolemia for up to two years, analyzed cumulative results after initiation of pitavastatin. The incidence of ADR was 6.1\%. Reported $\mathrm{ADR}$ is $12 \%$ for atorvastatin and $11 \%$ for rosuvastatin. ${ }^{76,77} \mathrm{At}$ two years, the incidence was $10.4 \%$, with $2.1 \%$ considered musculoskeletal and $1.0 \%$ attributable to liver dysfunction. The significant majority of ADR were classified as mild and less frequent than with other potent statins. These data appear to be consistent with a decreased incidence of ADR for pitavastatin compared with the other more potent statins available. A stratified analysis of the occurrence of ADR when administered with a variety of other drugs did not reveal any increase, even with concomitantly administered azole antifungals, macrolide antibiotics, coumarin anticoagulants, antiplatelet agents, antihypertensive, or diabetic drugs. This is most likely due to lack of competition for CYP metabolism. ADR with high-dose statins may be related to decreased coenzyme Q10 levels. A randomized, crossover study comparing pitavastatin $4 \mathrm{mg}$ and atorvastatin $20 \mathrm{mg}$ in 19 Japanese patients with heterozygous familial hypercholesterolemia revealed that plasma levels of coenzyme Q10 were reduced by atorvastatin $(-26.1 \%, P=0.0007)$ but not by pitavastatin $(-7.7 \%, P=0.39){ }^{78}$

As already discussed, pitavastatin, considered a nonCYP metabolized drug, does not appear to compete for, or inhibit, CYP metabolism, including CYP3A4, and so far has no documented significant drug-drug interactions. This addresses an extremely important issue for medical practitioners. Concern over interactions and potential toxicity often determines or modifies treatment decisions, especially for combination lipid modifying therapy. The possibility of myopathy, especially with statin-fibrate combinations, has prevented health care professionals from more aggressive risk assessment of combination dyslipidemia, such as atherogenic or diabetic dyslipidemia, and initiating combination drug therapy. This appears to be due to increased concern about myotoxicity with statin-fibrate combinations. However, careful review of the literature shows that the risk is slight, and most commonly secondary to a statin-gemfibrozil combination. ${ }^{18,79,80}$ The statin-fenofibrate combination does not appear to increase the risk of myopathy significantly ${ }^{81,82}$ or other organ toxicity. Fenofibric acid, recently FDA-approved with an indication for use with initial and moderate-dose statins, may also be preferable for combination use if the practitioner is concerned about potential toxicity ${ }^{83}$ or medicolegal issues.

There are reports of statins adversely effecting glucose metabolism. ${ }^{84,85}$ Seventy-nine statin-naïve diabetic patients with hypercholesterolemia received pitavastatin $1 \mathrm{mg}$ or $2 \mathrm{mg}$ for eight weeks. There were no statistically significant changes in fasting glucose or glycosylated hemoglobin $\left(\mathrm{HbA}_{1 \mathrm{c}}\right)$. Glycemic control was evaluated in patients with diabetes mellitus and receiving atorvastatin $10 \mathrm{mg}(\mathrm{n}=99)$, pravastatin $10 \mathrm{mg}(\mathrm{n}=85)$, or pitavastatin $2 \mathrm{mg}(\mathrm{n}=95)$ for three months. ${ }^{86}$ Random blood sugar and $\mathrm{HbA}_{1 \mathrm{c}}$ deteriorated mildly only in the atorvastatin-treated patients. Pitavastatin has no significant effect on parameters of glucose metabolism in normoglycemic or diabetic subjects.

Clinical trial safety data will have to be supported by larger, more diverse and longer-duration postmarketing surveillance.

\section{Conclusions}

The data for benefits of statins on clinical outcomes are powerful. There are clinical recommendations and 
guidelines from professional societies and governmentsponsored organizations defining lipid goals in patients with known atherosclerotic disease as well as those at increased risk. ${ }^{22}$ There may be more than 40 million Americans who fit these criteria, including a burgeoning population with increased waist circumference, metabolic syndrome, and diabetes mellitus, a known coronary artery disease risk-equivalent.

According to the NCEP ATP III recommendations, LDL-C remains the primary target of treatment unless TG are severely elevated ( $\geq 499 \mathrm{mg} / \mathrm{dL}$ ), which makes LDL-C calculated from the Friedenwald formula inaccurate. NCEP ATP III also contains recommended goals for TG, HDL-C, and non-HDL-C. Although these recommendations have clearly motivated health care professionals to address LDL-C in those at risk, it has also made them very LDL-centric and otherwise cautious or less concerned in their approach to more aggressive risk stratification and treatment. Most health care professionals appear to understand little about the role, current or potential, of other lipid, lipoprotein, and/or metabolic risk factors and treatment. We continue to initiate statin treatment at doses that will not achieve treatment targets often in those with known disease or acute events, and failure to titrate remains problematic. Another concern is the inordinate and role played by third-party payers in our selection or choice of pharmacologic treatment. Physicians and patients are often forced to choose drugs based on cost and not on efficacy or safety. As a result, not only is generic substitution the order of the day, but using a variety of subtle tactics and policies encouraging in-class substitution and movement to an entirely different class of drug when a generic choice is not yet available is also promoted. These policies interfere with the doctorpatient relationship and lead to medication switches often based on limited data.

There may be a variety of considerations in choosing a statin and dose, including:

- Initial LDL-C level and the percentage reduction needed to achieve target

- Need to address non-LDL factors

- Concomitant diseases or comorbid conditions

- Concomitant drug therapy

- Prior history of statin side effects or toxicity.

Other nonclinical issues, although important, including insurance coverage and cost, should not take precedence over at least initially selecting the most appropriate treatment possible.
Pitavastatin, the most recent HMG-CoA reductase inhibitor approved for patients, provides a new and potentially useful product on a variety of levels for those requiring LDL-C-lowering treatment. Pitavastatin has potent efficacy for lowering LDL-C, non-HDL-C, and apoB, rivaling atorvastatin and rosuvastatin, and is most effective for predictably increasing HDL-C in both the short and long term. Based on more aggressive NCEP treatment targets, its lipid-modifying efficacy alone makes it worthy of consideration for many patients. However, there are a variety of other considerations in choosing a statin, and pitavastatin may have advantages over other available drugs in specific patients. Side effects, even mild, have led to a significant incidence of statin discontinuation or nonadherence. Although pitavastatin is considered one of the more potent statins, its side effect and safety profile is excellent. In all published studies, ADR, including muscle and hepatic toxicity, are either lower or equivalent to other products available. This in large part may be due to its metabolism and elimination, which does not significantly utilize the CYP system, especially CYP3A4. Pitavastatin may have a substantial advantage versus other statins with regard to drug-drug interactions. This may be true for other lipid-modifying drugs or combination therapy, which appear underutilized in our population. Pitavastatin may allow for more aggressive treatment of mixed dyslipidemia, especially common in patients with metabolic syndrome and diabetes mellitus. Although some believe we should limit the number of drugs in a single class which receive FDA approval, taken to a logical conclusion, this policy would have limited the availability of more potent statins with improved efficacy, as well as other multiple beneficial effects. In addition, it is clear that certain drugs even within classes may have different side effect profiles in different individual patients. A huge clinical experience tells us that when a patient does not tolerate one statin there is a significant chance they will tolerate one of the other available drugs. Limiting choice would decrease goal attainment and potential benefit. Pitavastatin may be a useful addition to the HMG-CoA inhibitor class.

\section{Disclosure}

The author reports no conflict of interest in this work.

\section{References}

1. Endo A. The discovery and development of HMG-CoA reductase inhibitors. J Lipid Res. 1992;33:1569-1582.

2. Istvan ES, Deisenhofer J. Structural mechanism for statin inhibition of HMG-CoA reductase. Science. 2001;292:1160-1164.

3. Brown MS, Goldstein JL. A receptor-mediated pathway for cholesterol homeostasis. Science. 1986;232:34-47. 
4. Arad Y, Ramakrishnan R, Ginsberg HN. Lovastatin therapy reduces low-density lipoprotein apoB levels in subjects with combined hyperlipdemia by reducing the production of apoB containing lipoproteins: Implications for the pathophysiology of apoB production. J Lipid Res. 1990;31:567-582.

5. Buchwald H, Varco RL, Matts JP, et al. Effect of partial ileal bypass surgery on mortality and morbidity from coronary heart disease in patients with hypercholesterolemia. Report of the Program on the Surgical Control of the Hyperlipidemias (POSCH). N Engl J Med. 1990;323 946-955.

6. Lipid Research Clinics Program: The Lipid Research Clinics Coronary Primary Prevention Trial Results II. The relationship of reduction in incidence of coronary heart disease to cholesterol lowering. JAMA. 1984;251:365-374.

7. Baigent C, Keech A, Kearney PM, et al. Efficacy and safety of cholesterol-lowering treatment: Prospective meta-analysis of data from 90,056 participants in 14 randomised trials of statins. Lancet. 2005; 366:1267-1278.

8. Sukhova GK, Williams JK, Libby P. Statins reduce inflammation in atheroma of nonhuman primates independent of effects on serum cholesterol. Arterioscler Thromb Vasc Biol. 2002;22:1452-1458.

9. Plenge JK, Hernandez TL, Weil KM, et al. Simvastatin lowers C-reactive protein within 14 days: An effect independent of low-density lipoprotein cholesterol reduction. Circulation. 2002:106:1447-1452.

10. Nissen SE, Tuzcu EM, Schoenhagen P, et al. Statin therapy, LDL cholesterol, C-reactive protein, and coronary artery disease. N Engl J Med. 2005;352:29-38.

11. Ridker PM, Cannon CP, Morrow D, et al. C-reactive protein levels and outcomes after statin therapy. N Engl J Med. 2005;352:20-28.

12. Tsunekawa T, Hayashi T, Kano H, et al. Cerivastatin, a hydroxylmethylglutary 1 coenzyme A reductase inhibitor, improves endothelial function in elderly diabetic patients within 3 days. Circulation. 2001; 104:376-379.

13. Beckman JA, Liao JK, Hurley S, et al. Atorvastatin restores endothelial function in normocholesterolemic smokers independent of changes in low-density lipoprotein. Circ Res. 2004;95:217-223.

14. Laufs U, Wassmann S, Hilgers S, et al. Rapid effects on vascular function after initiation and withdrawal of atorvastatin in healthy, normocholesterolemic men. Am J Cardiol. 2001;88:1306-1307.

15. Nissen SE, Tuzcu EM, Schoenhagen P, et al. Effect of intensive compared with moderate lipid lowering therapy on progression of coronary atherosclerosis. JAMA. 2004;291:1071-1080.

16. Neuvonen PJ, Niemi M, Backman JT. Drug interactions with lipidlowering drugs: Mechanism and clinical relevance. Clin Pharmacol Ther. 2006;80:565-581.

17. Lilja JJ, Neuvonen M, Neuvonen PJ. Effects of regular consumption of grapefruit juice on the pharmacokinetics of simvastatin. Br J Clin Pharmacol. 2004;58:56-60.

18. McKenney JM, Ganz P, Wiggins BS, et al. In: Ballantyne CM, editor. Clinical Lipidology A Companion to Braunwald's Heart Disease. Philadelphia, PA: Saunders Elsevier; 2009.

19. Bays HE, Jones PH, Mohiuddin SM, et al. Efficacy and safety of fenofibric acid in combination with statin therapy for the treatment of patients with mixed dyslipidemia. J Clin Lipidol. 2008;2: 426-435.

20. Jones PH, Davidson MH, Stein EA, et al. Comparison of the efficacy and safety of rosuvastatin versus atorvastatin, simvastatin, and pravastatin across doses (STELLAR trial). Am J Cardiol. 2003;92:152-160.

21. McKenney JM, Jones PH, Adamczyk MA, et al. Comparison of the efficacy of rosuvastatin versus atorvastatin, simvastatin and pravastatin in achieving lipid goals (STELLAR trial). Curr Med Res Opin. 2003;19: 689-698.

22. The National Cholesterol Education Program Expert Panel. Executive Summary of the Third Report of the National Cholesterol Education Program (NCEP) Expert Panel on Detection, Evaluation, and Treatment of High Blood Cholesterol in Adults (Adult Treatment Panel III). JAMA. 2001;285:2486-2497.
23. Rosenson R, Otvos JD, Freedman DS. Relations of lipoprotein subclass levels and low-density lipoprotein size to progression of coronary artery disease in the Pravastatin Limitation of Atherosclerosis in the Coronary Arteries (PLAC-I) Trial. Am J Cardiol. 2002;90:89-94.

24. McKenney JM, McCormick LS, Schaefer EJ, et al. Effect of niacin and atorvastatin on lipoprotein subclasses in patients with atherogenic dyslipidemia. Am J Cardiol. 2001;88:270-274.

25. Sacks FM, Alaupovic P, Moye LA. Effect of pravastatin on apolipoprotein B and C-III in very low-density lipoproteins and lowdensity lipoproteins. Am J Cardiol. 2002;90:165-167.

26. Scandinavian Simvastatin Survival Study Group: Randomised trial of cholesterol lowering in 4444 patients with coronary heart disease: The Scandinavian Simvastatin Survival Study (4S). Lancet.1994;339:1349-1357.

27. The Long-term Intervention with Pravastatin in Ischaemic Disease (LIPID) Study Group: Prevention of cardiovascular events and death with pravastatin in patients with coronary heart disease and a broad range of initial cholesterol levels. N Engl J Med. 1998;339:1349-1357.

28. Heart Protection Study Collaborative Group: Effects of cholesterollowering with simvastatin on stroke and other major vascular events in 20,536 people with cerebrovascular disease or other high-risk conditions. Lancet. 2004;363:757-767.

29. Shepherd J, Blauw GJ, Murphy MB, et al. Pravastatin in elderly individuals at risk of vascular disease (PROSPER): A randomized controlled trial. Lancet. 2002;360:1223-1230.

30. Colhoun HM, Betteridge DJ, Durrington PN, et al. Primary prevention of cardiovascular disease with atorvastatin in Type 2 diabetes in the Collaborative Atorvastatin Diabetes Study (CARDS): Multicentre randomized placebo-controlled trial. Lancet. 2004;364:685-697.

31. Neil HA, DeMicco DA, Luo DJ, et al. Analysis of efficacy and safety in patients aged 65-75 years at randomization. Collaborative Atorvastatin Diabetes Study (CARDS). Diabetes Care. 2006;29: 2378-2384.

32. Hayward RA, Hofer TP, Vijan S. Narrative review: Lack of evidence for recommended low-density lipoprotein treatment targets: A solvable problem. Ann Intern Med. 2006;145:520-530.

33. Davidson MH, Maki KC, Pearson JA, et al. Results of the National Cholesterol Education (NCEP) Program Evaluation Project Utilizing Novel-E-Technology (NEPTUNE) II survey and implications for treatment under the recent NCEP writing group recommendations. Am J Cardiol. 2005;96:556-563.

34. McCrindle BW, Urbina EM, Dennison BA, et al. Drug therapy of high-risk lipid abnormalities in children and adolescents: A scientific statement from the American Heart Association Atherosclerosis, Hypertension, and Obesity in Youth Committee, Council of Cardiovascular Disease in the Young, with the Council on Cardiovascular Nursing. Circulation. 2007;115:1948-1967.

35. Saito Y. Critical appraisal of the role of pitavastatin in treating dyslipidemias and achieving lipid goals. Vasc Health Risk Manag. 2009;5: 921-936.

36. Kimata H, Fujino $H$, Koide $T$, et al. Studies on the metabolic fate of NK-104, a new inhibitor of HMG-CoA reductase (1): Absorption, distribution, metabolism and excretion in rats. Drug Metab Pharmacokinet. 1998;13:484- 498.

37. Morikawa S, Umetani M, Nakagawa S, et al. Critical appraisal of the role of pitavastatin in treating dyslipidemias and achieving lipid goals. J Atheroscler Thromb. 2000;7:138-144.

38. Aoki T, Nishimura H, Nakagawa S, et al. Pharmacological profile of a novel synthetic inhibitor of 3-hydroxy-3-methylglutaryl-coenzyme A reductase. Arzneimittelforschung. 1997;47:904-909.

39. Maejima T, Yamazaki H, Aoki T, et al. Effect of pitavastatin on apolipoprotein A-I production in HepG2 cell. Biochem Biophys Res Commun. 2004;324:835-839.

40. Fujino H, Yamada I, Shimada S, et al. Metabolic fate of pitavastatin, a new inhibitor of HMG-CoA reductase: Human UDP-glucuronosyl transferase enzymes involved in lactonization. Xenobiotica. 2003;33: $27-41$ 
41. Fujino H, Yamada I, Kojima I, et al. Studies on the metabolic fate of NK-104, a new inhibitor of HMG-CoA reductase (5): In vitro metabolism and plasma protein binding in animals and humans. Xenobio Metab Disp. 1999;14:415-424.

42. Nakaya N, Tateno M, Nakamura T, et al. Pharmacokinetics of repeated dose NK-104 (pitavastatin) in healthy elderly and non-elderly volunteers. J Clin Ther Med. 2001;17:957-970. Japanese.

43. Ando H, Tsuruoka S, Yanagihara H, et al. Effects of grapefruit juice on the pharmacokinetics of pitavastatin and atorvastatin. Br J Clin Pharmacol. 2005;60:494-497.

44. Sakaeda T, Fujino H, Komoto C, et al. Effects of acid and lactone forms of eight HMG-CoA reductase inhibitors on CYP-mediated metabolism and MDR1-mediated transport. Pharm Res. 2006;23:506-512.

45. Kajinami K, Mabuchi H, Saito Y. NK-104 a novel synthetic HMGCoA reductase inhibitor. Expert Opin Investig Drugs. 2000;9: 2653-2661.

46. Jacobson TA. The safety of aggressive statin therapy: How much can low-density lipoprotein cholesterol be lowered? Mayo Clin Proc. 2006; 81:1225-1231.

47. Saito Y, Teramoto T, Yamada N, et al. Clinical efficacy of NK-104 (Pitavastatin), a new synthetic HMG-CoA reductase inhibitor, in the dose finding, double blind, three-group comparative study. $J$ Clin Ther Med. 2001;17:829-855. Japanese.

48. Budinski D, Arneson V, Hounslow N, et al. Pitavastatin compared with atorvastatin in primary hypercholesterolemia or combined dyslipidemia. Clin Lipidol. 2009;4:291-302.

49. Saito Y, Yamada N, Teramoto T, et al. A randomized, double-blind trial comparing the efficacy and safety of pitavastatin versus pravastatin in patients with primary hypercholesterolemia. Atherosclerosis. 2002; 162:373-379.

50. Park S, Kang HJ, Rim SI, et al. A randomized, open-label study to evaluate the efficacy and safety of pitavastatin compared with simvastatin in Korean patients with hypercholesterolemia. Clin Ther. 2005;27: 1074-1082.

51. Ose L, Budinski D, Hounslow N, et al. Comparison of itavastatin to simvastatin in primary hypercholesterolemia or combined dyslipidemia. Curr Med Res Opin. 2009;25:2817-2828.

52. Nakaya N, Saito Y, Morisaki N, et al. Phase II clinical study of NK-104 (pitavastatin) in patients with hyperlipidemia. J Clin Ther Med. 2001;17: 789-806. Japanese.

53. Sasaki J, Ikeda Y, Kuribayashi T, et al. A 52-week, randomized, open label, parallel-group comparison of the tolerability and effects of pitavastatin and atorvastatin on high-density lipoprotein cholesterol levels and glucose metabolism in Japanese patients with elevated levels of low-density lipoprotein cholesterol and glucose intolerance. Clin Ther. 2008;30:1089-1101.

54. Kurihara Y, Douzono T, Kawakita K, et al. A large-scale, long-term prospective post-marketing surveillance of pitavastatin (LIVALO Tablet) - LIVALO Effectiveness and Safety (LIVES) Study. Jpn Pharmacol Ther. 2008;36:709-731.

55. Teramo T, Hitoshi S, Koutaro Y, et al. Effects of Pitavastatin (LIVALO tablet) on high density lipoprotein cholesterol (HDL-C) in hypercholesterolemia: Sub-analysis of LIVALO effectiveness and safety (LIVES) study. J Atheroscler Thromb. 2009;16:654-661.

56. Kawano M, Nagasaka S, Yagyu H, et al. Pitavastatin decreases plasma prebeta-HDL concentration and might promote its disappearance rate in hypercholesterolemic patients. J Atheroscler Thromb. 2008; 15:41-46.

57. Yokote K, Bujo H, Hanaoka H, et al. Multicenter collaborative randomized parallel group comparative study of pitavastatin and atoravastatin in Japanese hypercholesterolemic patients: Collaborative study on hypercholesterolemia drug intervention and their benefits for atherosclerosis prevention (CHIBA study). Atherosclerosis. 2008;201:345-352.

58. Nozue T, Michishita I, Ito Y, et al. Effects of statin on small dense lowdensity lipoprotein cholesterol and remnant-like particle cholesterol in heterozygous familial hypercholesterolemia. J Atheroscler Thromb. 2008;15:146-153.
59. Sone H, Takahashi A, Shimano H, et al. HMG-CoA reductase inhibitor decreases small dense low-density lipoprotein and remnant-like particle cholesterol in patients with type-2 diabetes. Life Sci. 2002; 72:2403-2412.

60. Koshiyama H, Taniguchi A, Tanaka K, et al. Kansai investigation of statin for hyperlipidemic intervention in metabolism and endocrinology investigators. Effects of pitavastatin on lipid profiles and high-sensitivity CRP in Japanese subjects with hypercholesterolemia. Kansai Investigation of Statin for Hyperlipidemic Intervention in Metabolism and Endocrinology (KISHIMEN) investigators. $J$ Atheroscler Thromb. 2008;15:345-350.

61. Libby P, Ridker PM, Maseri A. Inflammation and atherosclerosis. Circulation. 2002;105:1135-1143.

62. Ridker PM. Clinical application of C-reactive protein for cardiovascular disease detection and prevention. Circulation. 2003;107:363-369.

63. Motomura T, Okamoto M, Kitamura T. Effects of pitavastatin on serum lipids and high sensitivity $\mathrm{C}$-reactive protein in type 2 diabetic patients. J Atheroscler Thromb. 2009;16:546-552.

64. Hernandez-Perera O, Perez-Sala D, Navarro-Antolin J, et al. Effects of the 3-hydroxy-3-methylglutaryl-CoA reductase inhibitors, atorvastatin and simvastatin, on the expression of endothelin- 1 and endothelial nitric oxide synthase in vascular endothelial cells. J Clin Invest. 1998;101: 2711-2719.

65. Morikawa S, Takabe W, Mataki C, et al. The effect of statins on mRNA levels of genes related to inflammation, coagulation, and vascular constriction in HUVEC. J Atheroscler Thromb. 2002;9:178-183.

66. Kajinami K, Takekoshi N, Saito Y. Pitavastatin: Efficacy and safety profiles of a novel HMG CoA reductase inhibitor. Cardiovasc Drug Rev. 2003;21:199-215.

67. Kohno M, Shinomiya K, Abe S, et al. Inhibition of migration and proliferation of rat smooth muscle cells by a new HMG-CoA reductase inhibitor, pitavastatin. Hypertens Res. 2002;9:279-285.

68. Suzuki H, Yamasaki H, Aoki T, et al. Lipid lowering and antiatherosclerotic effect of NK-104, a potent 3-hydroxy-3-methylglutaryl coenzyme A reductase inhibitor, in Watanabe heritable hyperlipidemic rabbits. Arzneimittelforschung. 2000;50:995-1003.

69. Kitahara M, Kanaki T, Toyoda K, et al. NK-104, a newly developed HMG-CoA reductase inhibitor, suppresses neointimal thickening by inhibiting smoooth muscle cell growth and fibronectin production in ballon-injured rabbit carotid artery. Jpn J Pharmacol. 1998;77:117-128.

70. Hiro T, Kimura T, Morimoto T, et al. Effect of intensive statin therapy in regression of coronary atherosclerosis in patients with acute coronary syndrome: A multi-center randomized trial evaluated by volumetric intravascular ultrasound using pitavastatin versus atorvastatin. (Japan ACS Study). J Am Coll Cardiol. 2009;54:293-302.

71. Takashima H, Ozaki Y, Yasukawa T, et al. Impact of lipid-lowering therapy with pitavastatin, a new HMG-CoA reductase inhibitor, on regression of coronary atherosclerotic plaque. Circ J. 2007;71:1678-1684.

72. Nakamura T, Obata JE, Kitta Y, et al. Rapid stabilization of vulnerable carotid plaque within 1 month of pitavastatin treatment in patients with acute coronary syndrome. J Cardiovasc Pharmacol. 2008;51:365-371.

73. Flores NA. Pitavastatin: Nissan/Kowa Yakuhin/Novartis/Sankyo. Curr Opin Investig Drugs. 2002;3:1334-1341.

74. Elisaf M. XII International Symposium on Atherosclerosis. 2000 Jun 25-29; Stockholm, Sweden. IDrugs. 2000;3:1162-1163.

75. Kurihara Y, Douzono T, Kawakita K, et al. A large-scale, prospective post-marketing surveillance of pitavastatin (LIVALO tablet) - drug use investigation. J Pharmacol Ther. 2000;5:9-40. Japanese.

76. Komano N, Masaki M, Kawai H, et al. The safety and efficacy in postmarketing surveys of atorvastatin. Prog Med. 2005;25:131-142. Japanese.

77. McTaggert F. Comparative pharmacology of rosuvastatin. Atheroscler Suppl. 2003;4:9-14.

78. Kawashiri MA, Nohara A, Tada H, et al. Comparison of effects of pitavastatin and atorvastatin on plasma coenzyme Q10 in heterozygous familial hypercholesterolemia results from a crossover study. Clin Pharmacol Ther. 2008;83:731-739.

79. Jones PH, Davidson MH. Reporting rate of rhabdomyolysis with fenofibrate + fibrates versus gemfibrozil + any statin. Am J Cardiol. 2005; 95:120-122. 
80. Davidson MH, Armani A, McKenney JM, et al. Safety considerations with fibrate therapy. Am J Cardiol. 2007;99 Suppl:3C-18C.

81. Grundy SM, Vega GL, Yuan Z, et al. Effectiveness and tolerability of simvastatin plus fenofibrate for combined hyperlipidemia (The Safari Trial). Am J Cardiol. 2005;95:462-468.

82. Ellen RLB, McPherson R. Long-term efficacy and safety of fenofibrate and a statin in the treatment of combination hyperlipidemia. Am J Cardiol. 1998;81(4A):60B-65B.

83. Jones PH, Bays HE, Davidson MH, et al. Evaluation of a new formulation of fenofibric acid, ABT-335, co-administered with statins. Clin Drug Investig. 2008;28:625-634.
84. Sabatine MS, Wiviott SD, Morrow DA, et al. High-dose atorvastatin associated with glycemic control: A PROVE-IT TIMI 22 substudy. Circulation. 2004;110 Suppl I:S834.

85. Colhoun HM, Betteridge DJ, Durrington PN, et al. CARDS investigators. Primary prevention of cardiovascular disease with atorvastatin in Type 2 diabetes in the Collaborative Atorvastatin Diabetes Study (CARDS): Multicentre randomized placebo-controlled trial. Lancet. 2004;364:685-696.

86. Kawai T, Tokui M, Funae O, et al. Efficacy of pitavastatin, a new HMG Co A reductase inhibitor, on lipid and glucose metabolism in patients with Type 2 diabetes. Diabetes Care. 2005;28:2980-2981.

\section{Core Evidence}

\section{Publish your work in this journal}

Core Evidence is an international, peer-reviewed open-access journal evaluating the evidence underlying the potential place in therapy of drugs throughout their development lifecycle from preclinical to postlaunch. The focus of each review is to evaluate the case for a new drug or class in outcome terms in specific indications and patient groups

Submit your manuscript here: http://www.dovepress.com/core-evidence-journal

\section{Dovepress}

The manuscript management system is completely online and includes a very quick and fair peer-review system, which is all easy to use. Visit http://www.dovepress.com/testimonials.php to read real quotes from published authors. 